Recepción: 23 / 03 / 2018

Aceptación: 17 / 05 / 2018

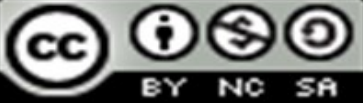

Publicación: 05 / 06 / 2018

Ciencias técnicas y aplicadas Artículo de Investigación

\title{
Voluntad racional de la arquitectura del siglo XXI: la ciudad del emprendimiento
}

Rational will of 21st century architecture: the city of entrepreneurship

\section{Vontade racional da arquitetura do século 21: a cidade do empreendedorismo}

Erick Bojorque-Pazmiño ${ }^{\mathrm{I}}$ jorge.bojorque@uleam.edu.ec

Alexis J. Macías-Loor ${ }^{\mathrm{II}}$ alexis.macias@uleam.edu.ec

Héctor G. Cedeño-Zambrano III hector.cedeno@uleam.edu.ec

Correspondencia: jorge.bojorque@uleam.edu.ec

${ }^{\text {I }}$ Magister en Estudios del Arte, Diploma Superior en Educación Universitaria por Competencias, Arquitecto, Docente en la Universidad Laica “Eloy Alfaro” de Manabí, Manta, Ecuador.

II Magister en Gerencia Educativa, Arquitecto, Docente en la Universidad Laica "Eloy Alfaro" de Manabí, Manta, Ecuador.

III Magister en Arquitectura Mención Diseño Urbano, Doctor en Arquitectura y Urbanismo, Arquitecto, Docente en la Universidad Laica "Eloy Alfaro” de Manabí, Manta, Ecuador. 


\section{Resumen}

En este artículo, se presenta el análisis del planteamiento de Claude Perrault, en el siglo XVII, de que la belleza es una convención anárquica a partir de los acontecimientos que llevaron a convertir al siglo XX en una época con voluntad racional. Este momento permitió que la razón pusiera en evidencia los órdenes clásicos de composición edilicia, separando la arquitectura de las artes y llevándola por el derrotero de la construcción, hasta la Bauhaus para las edificaciones y la Carta de Atenas en el caso de ciudades. Entre los resultados del análisis hermenéutico de la literatura, se pudo constatar que el proceso racional del hombre acerca de la belleza se convirtió en un esquema universalizante que ha convertido los modos sociales en catastróficos. También, fue posible develar que, desde finales del siglo XX, las reflexiones traducidas desde la antropología llevaron a tener un atisbo de consciencia de lo que se estaba haciendo con el ser humano a través de las edificaciones y las ciudades. Por otro lado, se presenta la consciencia como una nueva voluntad de época en la entrada del siglo XXI, que marca un nuevo modo de pensamiento y acción social basado en la auto edificación personal. Es la ciudad del emprendimiento la que hace su aparición como norte argumentativo inicial de esta transformación. Para ello, se propone como herramienta, para el arquitecto consciente, la normativa urbana que usada con consciencia permitirá, de forma puntual ir determinando cambios cualitativos en una ciudad vocacional, empática y vivificante.

Palabras clave: Arquitectura; moderno; consciencia; emprendimiento; normativa.

\section{Abstract}

In this article, we present the analysis of the approach of Claude Perrault, in the seventeenth century, that beauty is an anarchic convention from the events that led to turn the twentieth century into an era with rational will. This moment allowed the reason put in evidence the classical orders of building composition, separating the architecture of the arts and taking it through the course of construction, to the Bauhaus for buildings and the Charter of Athens in the case of cities. Among the results of the hermeneutic analysis of literature, it was found that the rational process of man about beauty became a universalizing scheme that has converted social modes into catastrophic ones. Also, it was possible to reveal that, since the end of the 20th century, reflections translated from anthropology led to a glimpse of awareness of what was being done with human beings through buildings and cities. On the other hand, consciousness is 
presented as a new epochal will at the beginning of the 21 st century, which marks a new way of thinking and social action based on personal self-edification. It is the city of entrepreneurship that makes its appearance as the initial argumentative north of this transformation. To do this, it is proposed as a tool, for the conscious architect, the urban regulations that used with awareness will allow, in a timely manner, to determine qualitative changes in a vocational, empathetic and revitalizing city.

Keywords: Architecture; modern; conscience entrepreneurship; normative.

\section{Resumo}

Neste artigo, apresentamos a análise da abordagem de Claude Perrault, no século XVII, de que a beleza é uma convenção anárquica a partir dos acontecimentos que levaram a transformar o século XX numa era de vontade racional. Este momento permitiu que a razão colocasse em evidência as ordens clássicas de composição do edifício, separando a arquitetura das artes e levando-a ao longo da construção, a Bauhaus para edifícios e a Carta de Atenas no caso das cidades. Entre os resultados da análise hermenêutica da literatura, constatou-se que o processo racional do homem sobre a beleza tornou-se um esquema universalizante que converteu os modos sociais em modos catastróficos. Além disso, foi possível revelar que, desde o final do século XX, reflexões traduzidas da antropologia levaram a um vislumbre da consciência do que se fazia com seres humanos por meio de edifícios e cidades. Por outro lado, a consciência é apresentada como uma nova vontade histórica no início do século XXI, que marca uma nova maneira de pensar e ação social baseada na auto-edificação pessoal. É a cidade do empreendedorismo que aparece como o norte argumentativo inicial dessa transformação. Para tanto, propõe-se como ferramenta, para o arquiteto consciente, que as regulamentações urbanas, utilizadas com consciência, permitam, em tempo hábil, determinar mudanças qualitativas em uma cidade vocacional, empática e revitalizante.

Palavras chave: Arquitetura; moderno; consciência empreendedorismo; normativo.

\section{Introducción}

Cuando la arquitectura trasciende la acción propia de los arquitectos y se vuelve ámbito de otros profesionales y de otros campos del conocimiento, entonces la arquitectura se vuelve relevante para una época, dejando de lado la acción personal y las posturas estéticas de los profesionales 
para convertirse en un modo social de vida. Sztulwark, arquitecto, al respecto ilustra tal postura cuando dice: "...que una época es arquitectónica cuando la reflexión sobre la materia es recurso, socialmente percibido y extendido, para pensar modalidades de habitar, formas de vivir" (Sarquis, 2006: 122).

Una edificación es la clara expresión de la metacognición personal del arquitecto que la ha proyectado, de manera consciente cuando su propuesta tiene el privilegio de ser relevante por la libre iniciativa evidente en su creación o, de manera inconsciente cuando el proyecto es el resultado del miedo y de la irreflexiva imitación. En ambos casos el proyecto dado a luz, influye en las estructuras sociales de distinta manera.

"Toda ciudad es la extensión del edificio" (Bojorque, 2017: 103), reza el segundo principio de la arquitectura energética consciente, que nos indica que cualquier edificio tiene la capacidad de influir decididamente en su entorno al momento de ser insertado en él, como una persona lo hace ante un grupo social.

En caso de indiferencia, el colectivo estima en su crítica intrínseca de uso que el edificio no ha dado la talla sino de un elemento más del común denominador y que su planteamiento descuidado no ha considerado ni los paradigmas evidentes del modo social en el que se adentra. Su falta es seguir las convenciones estéticas, disposicionales y técnicas.

$\mathrm{Si}$, un edificio logra tocar una fibra sensible del acontecer social, al evidenciar estigmas repetitivos y obviados por la sociedad, o al mostrar nuevos postulados que rompen las convenciones formales o estéticas como en su tiempo lo hizo Perrault al plantearse un sexto modelo de columnatas clásicas propuestas en la fachada del edificio del Louvre en París, entonces su acción produce aceptación e inmediata apropiación y se vislumbra como fuente de nuevos pensamientos y hasta posturas que trasciende el devenir de los tiempos. Pero, esto es un proceso.

\section{Desarrollo}

\section{La voluntad de una época}

Claude Perrault entre los años de 1660 y 1670 propuso una doble columnata para el Louvre que manteniendo las consignas clásicas, enfrentaba a la comunidad de la época a un nuevo 
planteamiento formal pues había descubierto tras observar las mediciones realizadas por Antoine Desgodets de las edificaciones de la Roma antigua de los Césares, que, al usar la supuesta proporción y métrica clásica, no existía sino una convención irreflexiva de belleza. Las distintas medidas de templos, columnas, detalles, no tenían relación sino en el nombre y en la composición, por lo que se atrevió a romper el mito constructivo evidenciándolo como nuevo orden clásico.

Este acto de Perrault, es tan interesante y poderoso en arquitectura como fue para el arte el gesto de Duchamp y su consiguiente expresión artística en el ready-made. Perrault había abierto la posibilidad de enfrentar la belleza a un juzgamiento. Lo siguiente que se verifica en la historia es una constante declaración de ruptura a los cánones establecidos. Lo haría Violet Le Duc al buscar la verdad a través de la programación de necesidades y de la estética de la expresión de los materiales, en su caso el hierro; también lo haría Ruskin invocando la totalidad de una obra arquitectónica y artística en pos de un equilibrio entre lo natural-humano y lo artificial-industrial. Posteriormente los arquitectos modernos serían quienes también juzgarían la belleza clásica y los planteamientos rurales pintoresquistas, para ceder ante la lógica y la razón de la construcción industrializada.

Un acto relevante y trascendente para la humanidad lo hace la postura de un arquitecto y su edificio que al así serlo lo convierten en tema de relevancia ante la opinión pública, ya no solo de arquitectos y versados en la construcción sino de todos los conocimientos y sus expertos.

Veamos como romper las convenciones clásicas en urbanismo que llevaron en el siglo XIX a transformaciones tan significativas en mal o en bien de por ejemplo Londres, Roma, París, Berlín, Viena, Barcelona, con planes de ordenamiento que se desentendían de las implicaciones constructivas del medio evo y pregonaban la salud, la defensa, la civilización y la educación. Es tal este precursor histórico que para la fecha las ciudades actuales tienen el mismo esquema panóptico que Haussmann delineó en Paris durante el reinado de Napoleón Tercero a finales del siglo XIX, por ejemplo.

Actos arquitectónicos que se convierten en épocas arquitectónicas como lo dice el arquitecto Sztulwark. En el siglo XX los arquitectos modernos nacidos del pensamiento técnico de la industria y grandemente influenciados por los aportes de la ingeniería en la construcción y en la 
creación de nuevos espacios cuya génesis se encontraba en el uso del hierro, sucumbieron ante la idea de industrialización de la arquitectura, separándola del arte, de la mística, de la filosofía, que eran su generatriz mayúscula, para sucumbir ante la ciencia emparejada a las técnicas industriales. Nacía la voluntad del siglo XX, la idea de la "máquina para vivir"

Como vemos "la modernidad, es una época arquitectónica" (Sarquis, 2006: 121) pues convivieron en ella propuestas y contrapropuestas en el arte, la técnica y los programas sociales. Una época cuya voluntad era la razón y con ella el dominio de todos los estamentos de planificación y programación social. Esta voluntad veía al ser humano trascendido a través del positivismo que generaba la técnica y la industria y que tenía que dictar las reglas del convivir.

"La nueva arquitectura, la verdadera Arquitectura, debe resultar de una estricta adherencia a la lógica, a la racionalidad. Un rígido constructivismo, debe dictar las reglas" (Mera, 2016: 66).

La construcción ya era un tema que la Bauhaus en la primera mitad del siglo XX, como escuela de arquitectura, había tomado en consideración. Walter Gropius buscaba esa diligente entrega de la arquitectura a la industria. La vivienda en un inicio era el lugar donde trabajaba el arquitecto creador de una totalidad bastante convergente con el pensamiento del Art Noveau, pero la industria ofrecía un nuevo campo que la arquitectura veía como el detonante de lo que sería el futuro social.

La construcción, la razón, la lógica, la prefabricación y la sistematización fueron los elementos claves de la voluntad de la época del siglo XX y la arquitectura tenía que responder a ellos. Nacía el arquitecto íntegro, aquel arquitecto que veía en sus edificios la trascendencia de sus propuestas personales y en la ciudad su laboratorio racional cuya máxima expresión fue dictada por el arquitecto suizo Le Corbusier en la Carta de Atenas gestada en 1933. El CIAM (Congreso internacional de Arquitectura Moderna) fue su catapulta y posteriormente su mausoleo.

Para finales del siglo XX el positivismo original que la técnica y la razón ofrecían al mundo había sido desbarato con los terribles acontecimientos de la Segunda Guerra Mundial. La temida bomba atómica transformó la voluntad positiva en la carestía de la destrucción. Los anhelos quedaron truncos pues la técnica que pregonaba mejores días para la humanidad se había convertido en el hecho clave para la masiva aniquilación del ser humano. 
Las ciudades estaban caotizadas con las ideas modernas de "habitar, trabajar, circular y recrearse" pues habían cedido el espacio a la anarquía del automóvil y la funcionalidad de la urbe. Los ciudadanos se enfrentaban a ciudades llenas de vehículos y a grandes edificios sin mayor análisis que la técnica constructiva.

Las viviendas se arreglaban de la mejor manera ante la idea del espacio mínimo y de la modulación. No se pensaba en el ser humano sino en cómo mejorar la prefabricación de los usos y los modos de habitar.

Las personas se estaban muriendo anímicamente en ciudades y viviendas hechas para las máquinas y no para la convivencia, la empatía, la solidaridad, la contemplación y la autorrealización. El ser humano se pregunta sobre su situación y desarrollo encontrando las respuestas en culturas y campos del conocimiento diferentes, se introduce la idea de contexto, humanidad, significados.

"Vivimos en un mundo de significados. La visión de cualquier ser humano, de cualquier animal, planta $\mathrm{u}$ objeto resuena en nuestra mente, aunque rara vez somos totalmente conscientes de esas reverberaciones, Es necesario un artista para que nos fijemos en el mensaje de la realidad" (Mera, 2016: 11)

Termina el siglo XX con grandes inquietudes y con una marisma de conceptos y posturas irrelevantes en el arte y la arquitectura que sopesan siempre la razón, asimilándola nuevamente a través de la alta tecnología; o burlándose a través de la posmodernidad; o encarándola a través de la consciencia.

La consciencia se vuelve relevante a finales del siglo XX e inicios del siglo XXI. La ciudad que ha sido fragmentada por la separación conceptualizada de la razón en funciones catastróficas que han convertido las urbes en gigantescos lugares donde el caos vehicular, la contaminación y la agresión son la única opción y que las personas de seres humanos involucionaron en seres productivos sin mayor aspiración que las vacaciones de fin de semana; reflexiona sobre sí misma y se pregunta sobre su sentido como ente receptor de la vida humana. Se hace consciencia en el detenerse, en el uso de transporte masivo y alternativo, en el mirar a la gente. Se insta al uso de vehículos con sistemas motorizados no contaminantes, las vías peatonales y carriles bici. La 
ciudad retira espacio al automóvil y reverdece el uso público de contacto humano. La consciencia gana cada vez más derroteros.

A la par, las personas hacen consciencia de lo que comen, de su condición anímica, de su educación y preparación. El pensamiento y la voluntad del siglo XX racional ceden ante la enérgica acción de la comprensión de la propia situación. El ser humano no es una masa social sino una individualidad creadora.

Azara (2015), acicala esta lección al comprender, por ejemplo, que las ciudades ancestrales egipcias eran, no un hecho particular racional sino la convergencia de eventos metafísicos y místicos que resultaban engalanando los atributos de tal deidad encargada de la edificación, en este caso Ptah. Por su parte Azara (2015), señala "Las labores edilicias de Ptah tenían también como fin la edificación de un templo particular: la formación de sí mismo. Ptah se cultivaba a través de sus acciones edificantes" (p. 63)

La certeza de la intervención humana por la racionalidad de sus acciones llega a un punto sin retorno. La humanidad quiere una ciudad, arquitectura relevante y consciente, sostenibilidad, sustentabilidad, armonía natural, energías no industriales sino sensibles y generadoras de auto edificación personal.

La belleza del canon clásico sostenida por convenciones fue destruida por Perrault y el pensamiento se permitió objetar todo lo dictado por la sociedad. La belleza de la razón sostenida por la técnica moderna ha sido destruida por el pensamiento consciente y el ser humano se permite valorar lo objetivo, pero con una valoración no universal sino individualizante. Se repite el uroboro histórico, pero esta vez la voluntad de la época del siglo XXI será la consciencia. Como dice Cheng: "No es tarea fácil discernir las verdaderas bellezas de las falsas, ni de formular criterios que permitan establecer los verdaderos valores" (Bojorque, 2017: 40). Si la belleza fue buscada por la razón, la verdad será el gran evento del siglo XXI y no será tarea fácil.

\section{La ciudad del emprendimiento}

La humanidad moderna entiende por ciudad a aquel planteamiento que los arquitectos del CIAM hicieran allá por 1943. Una ciudad separada en distintas funciones. Esa es la ciudad moderna. Las 
visiones antropológicas de los años setentas cambiaron la organización de la ciudad, pero no la esencia de ella. Las edificaciones resultaron ser siempre las mismas.

El emprendimiento es aquella actividad que la persona ejerce desde su vocación hacia el exterior de sí. Un servicio, una artesanía, una pequeña industria familiar, un negocio, es un emprendimiento. En el emprendimiento la ciudad manifiesta la laboriosidad de los suyos sin la dependencia del empleo que la ciudad industrial y la ciudad moderna crearon en sus tiempos respectivos. El emprendedor se profesionaliza y ejerce su actividad en su estudio en donde atiende a un público selecto. Muy al contrario, el empleado moderno buscaba afanosamente el trabajo generado por otro. La ciudad moderna necesitaba de grandes empresas y grandes corporaciones para todos aquellos habitantes de la urbe. La distribución de la riqueza era inequitativa y desequilibrada.

El emprendedor no es nuevo. La ciudad pre-moderna tenía en sí la esencia de la vocación y de la disciplina. Las familias tenían sus modos de supervivencia y crecimiento en base de su ancestro. La disciplina dictaba entonces que el panadero tendría vástagos que ejercieran dicha labor. Así mismo los constructores, los educadores, los abogados, los negociantes. Muy ejemplificante de esto, en escala superlativa, es la cultura japonesa cuyas familias, por ejemplo, de ceramistas que han llegado a convertirse en grandes productores de micro circuitos electrónicos de cerámica, en base a las tradiciones artesanales ancestrales que han superado el tiempo y la pereza.

No es difícil recordar como al salir de casa hasta hace unos cuantos años en Ecuador, los emprendimientos estaban a la orden desde la puerta de al lado. Panaderos, cerrajeros, ebanistas, comerciantes, talabarteros, estilistas, profesionales. Era una sociedad rica en opciones como rico es el acervo humano en su totalidad.

Los empleos y las grandes empresas vinieron a dar al trasto con esos emprendimientos. ¿Cómo podría competir el zapatero de la esquina con los precios ofertados por la gran empresa importadora? ¿Cómo el sastre de barrio ante el vendedor en serie? El emprendimiento en la vida moderna fue siendo destruido paulatinamente.

Hoy en día las ciudades carecen de emprendimiento y esto es gravísimo, pues ¿en dónde el ser humano da rienda suelta a su vocación? ¿En dónde el jardinero expone sus creaciones y vive de ello? 
La razón y la universalización moderna acabaron con la vocación humana. Lo consciente es nuevamente hacer surgir dicha vocación, pues el ser humano que se auto edifica es un ser humano relevante.

La ciudad del emprendimiento entonces es la ciudad consciente vocacional. Los seres humanos necesitamos de estos espacios en dónde auto edificarnos y la ciudad consciente ha de entregarlos. La ciudad moderna entrega a la ciudadanía grandes auto vías, lugares para caminar sin detenerse y grandes industrias donde emplearse. La ciudad consciente ha de entregar lugares para detenerse y contemplar, espacios donde interactuar, conocerse y hacerse empático y lugares suficientes para que el emprendedor vocacional puede realizarse, junto a ellos. El arquitecto ha de reflexionar en esto, pues es él quien crea esos lugares y permite las facilidades para que vivan.

José, carpintero, padre del mesías cristiano, llevaba en su nombre la esencia del arquitecto entregado a la gran obra..."Su nombre Yoseph significaba en hebreo "el que aumenta o acrecienta la vida", "el que da vida", nombre adecuado para un sumo creador, un arquitecto" (Azara, 2015: 108)

\section{La normativa urbana}

La herramienta de difusión, de convencimiento del arquitecto moderno, en general su estrategia, tuvo que ver con los manifiestos y los textos escritos, generalmente en revistas temáticas. Adolf Loos, por ejemplo, posibilitó el ascenso de su pensamiento vienés de secesión, mediante publicaciones periódicas en diarios y revistas vienesas. Le Corbusier utilizó este seudónimo mientras escribía textos pos cubistas con Ozenfant, para difundir sus proclamas. Hablamos también de su manifiesto la "Carta de Atenas". Los escritos y los textos eran las herramientas con las que lograron infiltrar sus ideas estos arquitectos modernos.

Los arquitectos conscientes tendremos como herramienta principal la comprensión. Comprensión nacida de la plena atención en las impresiones que la vida deja en nuestros sentidos. Esa consciencia generada nos permitirá lograr un nuevo estrato de vida para nuestros congéneres.

La comprensión no es un hecho metafísico subjetivo, va más allá de las posibilidades etéreas. Es un eficiente articulador entre lo interno y lo externo. La comprensión se define con parámetros. Estos parámetros para un arquitecto son las constantes urbanas. 
La normativa urbana es la constante apropiada para comprender y actuar en las urbes. La normativa urbana es la herramienta del arquitecto consciente del siglo XXI. Para el arquitecto moderno la ciudad y la vivienda eran hechos compositivos moldeables de manera total y completa. Veamos la Unidad de Habitación de Marsella de Le Corbusier. No había sino arrogancia al pensar que un profesional podía cambiar el mundo simplemente porque podía expresar sus pensamientos de manera secuencial en un texto. El arquitecto moderno sentía que la arquitectura se sintetizaba en diseñar un módulo habitacional que luego repetido se convertía en un edificio y luego éste repetido en un barrio y luego estos repetidos en una ciudad. Suma y resta de elementos modulares eran para la él la vida de las personas.

El arquitecto consciente sabe los límites del diseño y comprende que la ciudad es un ser complejo y lleno de atributos y valores que no son asimilables por un solo profesional, sino que requiere de ingentes investigadores y que aun así sorprende por su inducción al cambio, a la transformación. Un simple reflujo de vías, un nuevo centro comercial, un evento natural, son capaces de mostrar cómo todas las proyecciones son insuficientes $\mathrm{y}$ hasta inadecuadas en su pensamiento $\mathrm{y}$ aplicación.

La ciudad del emprendimiento quiere normativas que fomenten las edificaciones con oferta de espacios a la calle para oficinas, restaurantes, talleres, comercios. Normas que aseguren arriendos seguros y sin afán de lucro. Estos espacios combinados armoniosamente por normativa con la vivienda, las oficinas, las industrias y que permitan que el ciudadano común pueda vivir y pueda conocer a sus vecinos y sus conciudadanos para un habitar mejor y digno. Normativas que:

- Regule la oferta de locales para el emprendimiento por zonas de la ciudad, en planta baja.

- Beneficie a los propietarios reduciendo impuestos prediales de los sitios, edificaciones, que oferten locales para el emprendimiento en plantas bajas y primeras altas.

- Fomente locales de trabajo compartido en la ciudad.

- Capacite a la ciudadanía en el emprendimiento.

- Adjunte a los locales de emprendimiento plazas y plazoletas donde se ejecuten actividades sociales. 
- Incentive el recorrido artesanal, artístico, de emprendimiento en la ciudad.

- Limite la acción acaparadora de las grandes empresas y consorcios, para salvaguardar la vocación de los ciudadanos.

Este planteamiento es solamente el inicio de muchos otros sobre la consciencia ganando terreno a las estructuras creadas por la razón a través de la modernidad. Serán muchos los tópicos y la auto edificación personal que sirven como detonante de una avalancha creativa vocacional.

OFERTA LOCALES EMPRENDIMIENTO

REDUCCIÓN DE IMPUESTOS

COWORKING

CAPACITACIÓN

PLAZAS Y PLAZOLETAS

RECORRIDOS CIUDADANOS

SALVAGUARDAR LA VOCACIÓN

Cuadro 1. Normativa Urbana para la Ciudad del Emprendimiento Fuente: Elaboración del autor 


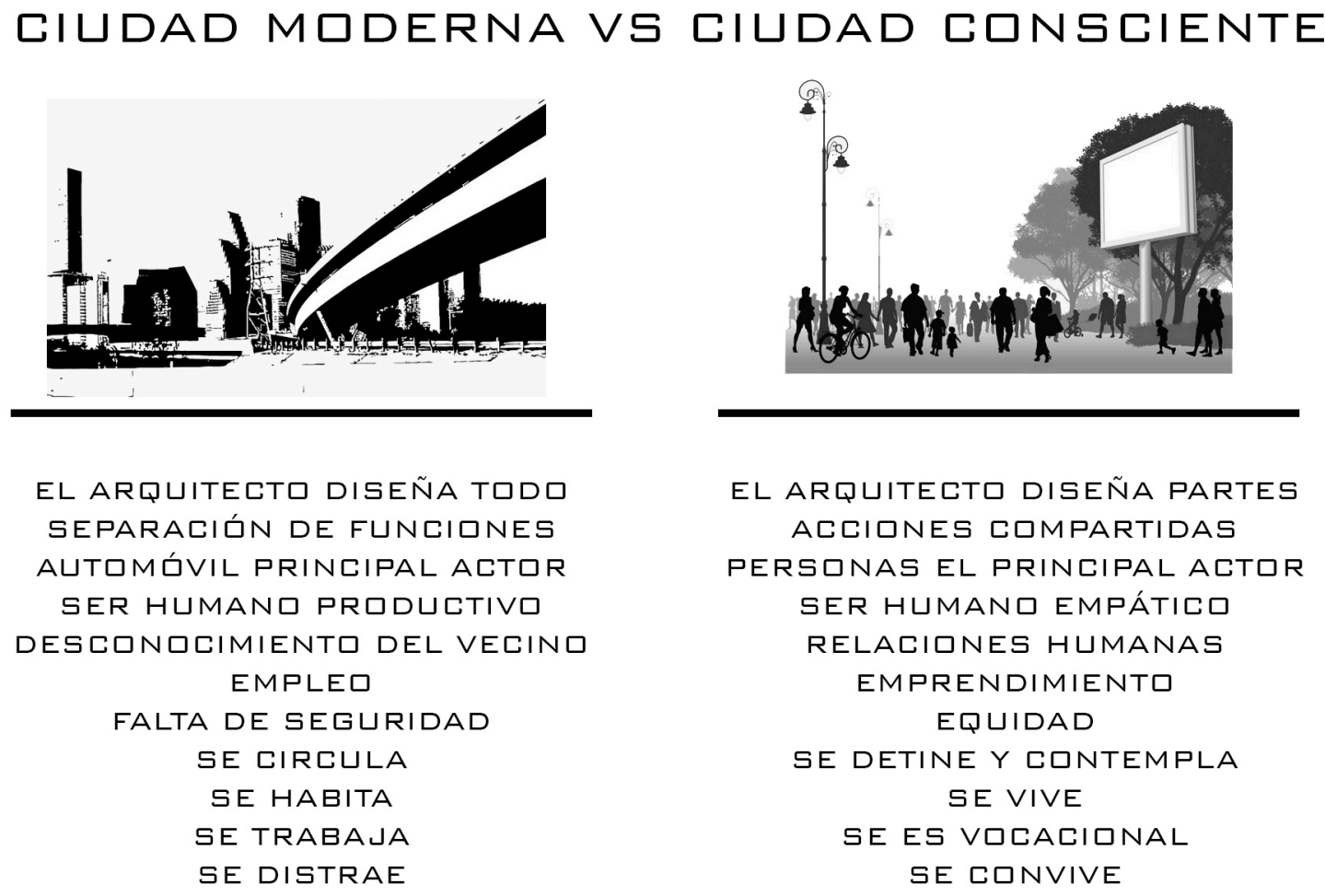

Imagen 1. Ciudad Moderna vs Ciudad Consciente

Fuente: elaboración del autor.

\section{Conclusiones}

- La influencia del edificio y por tanto del pensamiento del arquitecto es tal, que inmediatamente los efectos de su gestación constructiva dejan relucir la acción social de indiferencia, rechazo o apropiación colectiva del inmueble.

- El arquitecto y sus modos de diseño han sido relegados al contento masivo y son la expresión de esa masa irrelevante para la humanidad cuando el edificio es indiferente y su uso es aquel al que las personas están acostumbradas a percibir, caso contrario si el edifico logra tocar una fibra sensible del acontecer social. 
- La acción del arquitecto produce aceptación e inmediata apropiación y se vislumbra como fuente de nuevos pensamientos y hasta posturas que trasciende el devenir de los tiempos si logran evadir los estigmas repetitivos y obviados por la sociedad.

- La educación arquitectónica se entregó a la construcción como tal y el elemento clave fue la fabricación de cada una de sus partes por medio de la industria, que se veía beneficiada con nuevos diseños de objetos, decoraciones e insumos propios de la construcción.

- La vivienda quedó relegada a la construcción y a las grandes intervenciones por la reconstrucción de los países europeos, tras las posguerras permitieron dar a flote con estas ideas de modulación y prefabricación sistemática convirtiéndose en un importante tema social.

- Una ciudad consciente es una ciudad distinta, pues no existen las funciones separadas, existe la convivencia. En la ciudad consciente no existe el trabajo lejos de casa, existe la labor en la propia vivienda, puede ser considerada la ciudad del emprendimiento.

- La intervención consciente es paulatina y decididamente puntual y en ello se versa la normativa urbana. La normativa urbana usada con inteligencia, con diligencia y creatividad puede hacer de una parte de la ciudad, un elemento trascendente.

- No se debe seguir usando la normativa urbana a través de la visión del siglo XX que reducía su acción a los principios universales del hábitat moderno. Esto ha hecho que ciudades extrañas y distantes en el globo terráqueo, se vean idénticas, con los mismos errores y catástrofes.

\section{Referencias Bibliográficas}

Azara, P. (2015). Cuando los arquitectos eran dioses. Madrid: Catarata.

Bojorque, E. (2017). Hacia un estilo estético en la arquitectura: La Reticencia. Manta. Casa Editora Del Polo. Impreso.

Mera, J. (2016). Un círculo es un círculo y otros escritos. Buenos Aires: Diseño.

Sarquis, J. (2006). Arquitectura y modos de habitar. Buenos Aires: Nobuko. 